\title{
昆蟲に由る䫀菌の傳播に就て
}

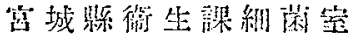

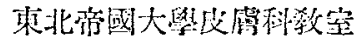

徫生課长淺海修藏

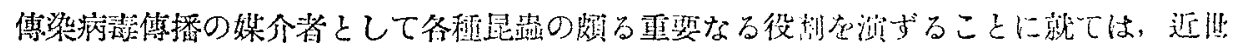

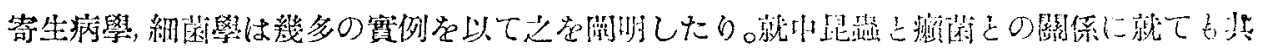

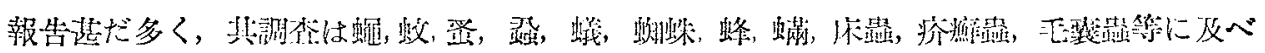

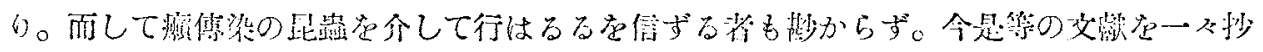

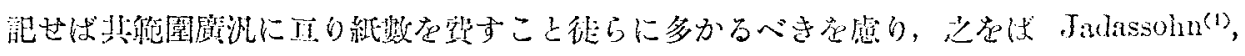

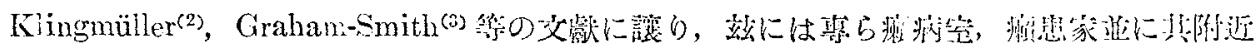

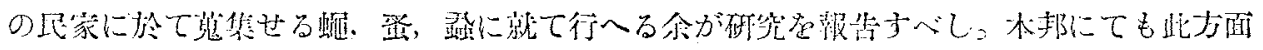

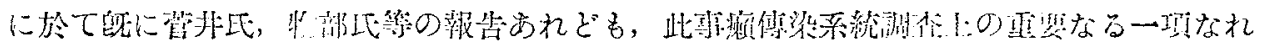

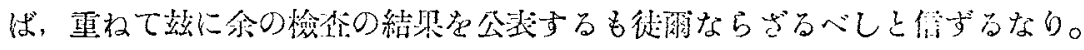

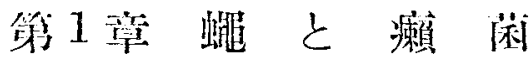

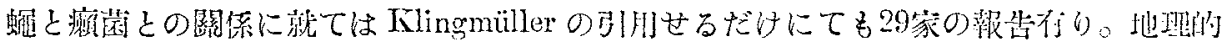

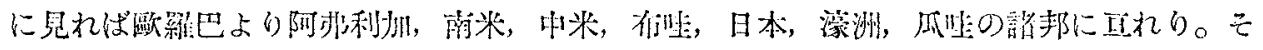

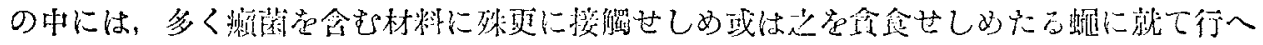

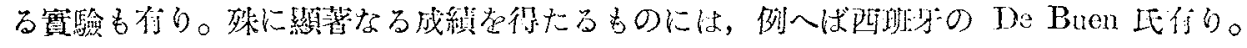

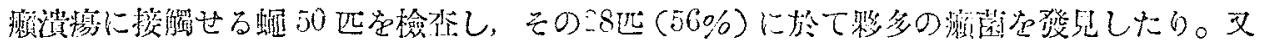

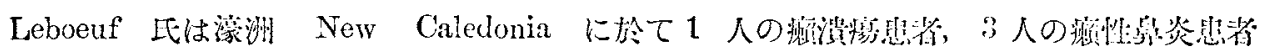

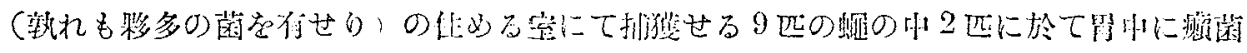

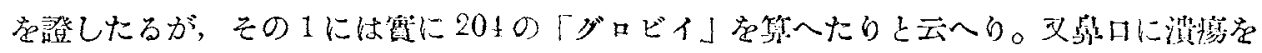

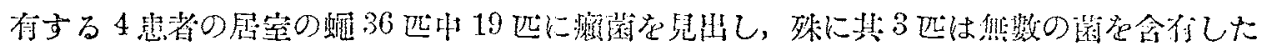

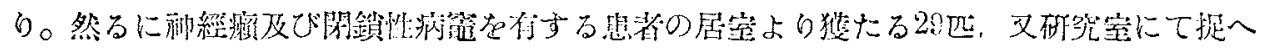

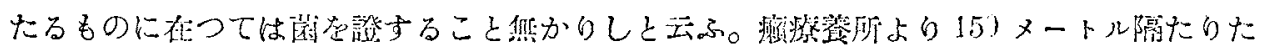
る地域に得たる23匹に在つても同柡なりしと。

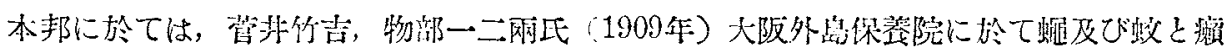
( 17$)$ 


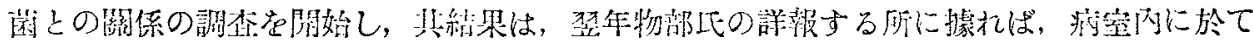

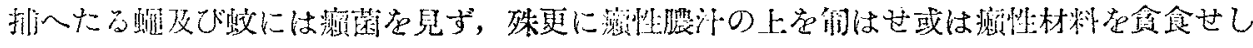

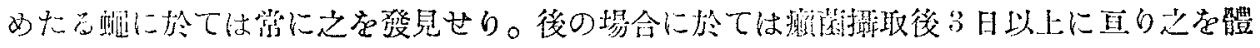

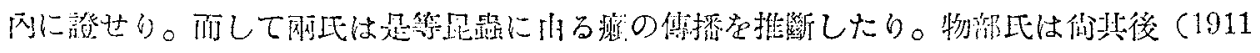

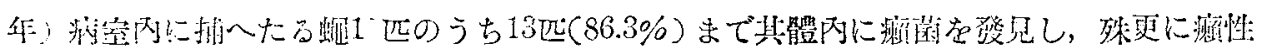

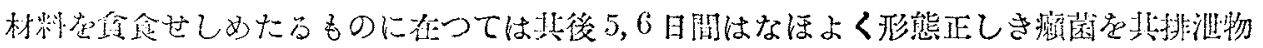

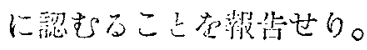

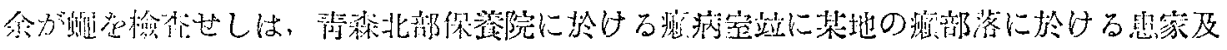

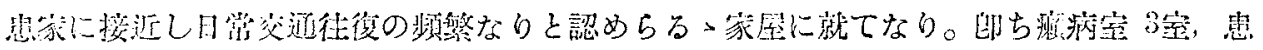

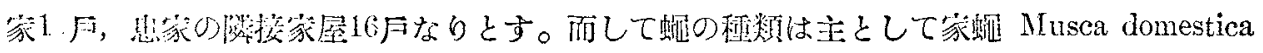
なり。

\section{甲、檢 查 方 法}

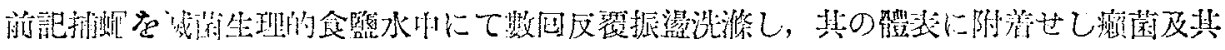

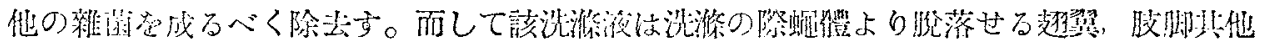

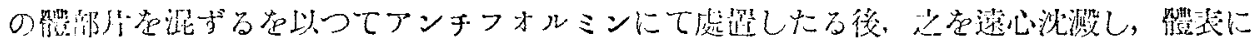

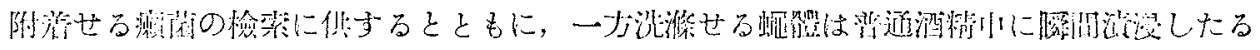

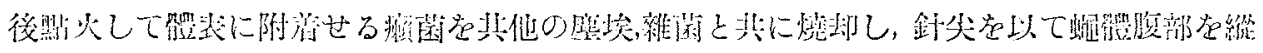

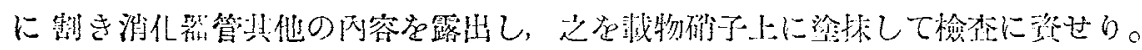

\section{乙、蠅の腸防容㭘䆞成䌐}

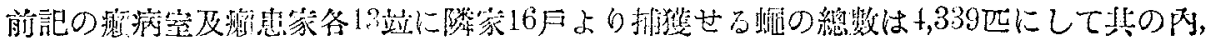

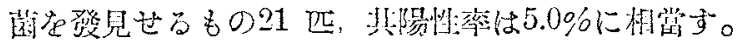

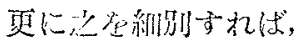

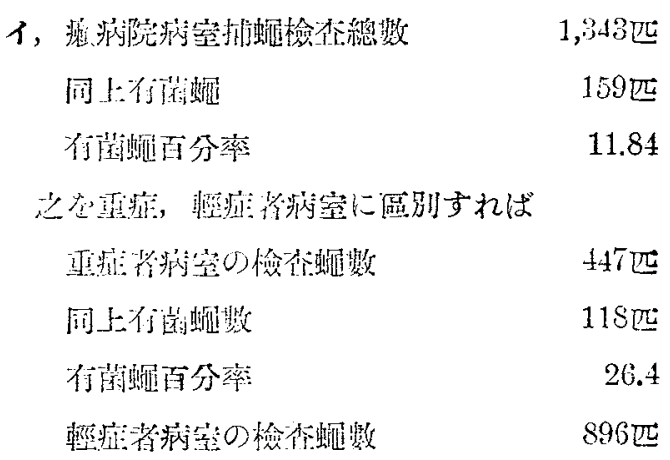




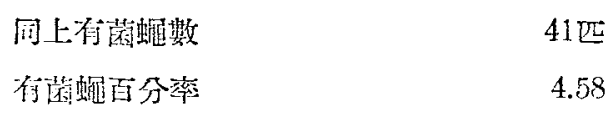

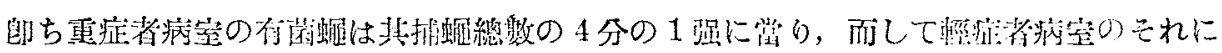

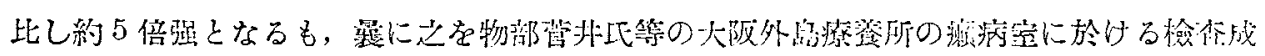

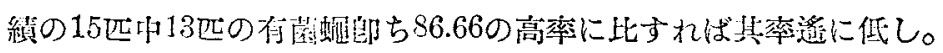

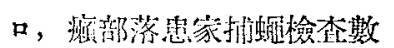

1,786 匹

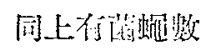

41匹

付菌䗆百分率

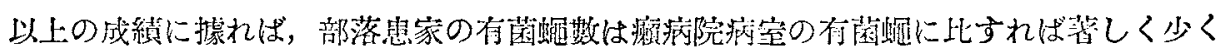

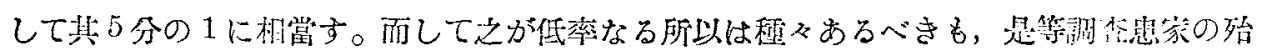

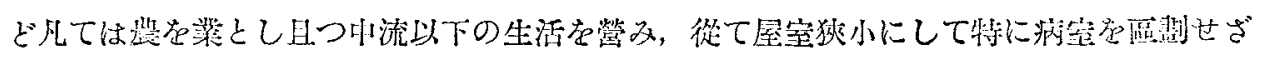

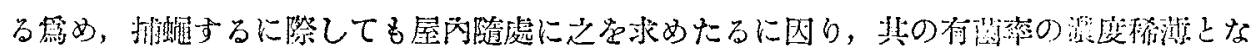
れるものと思若せらる。

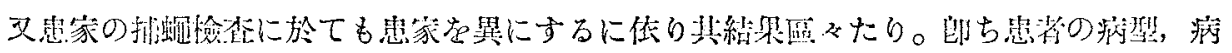

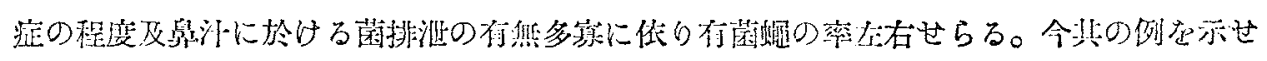
ば石の如し。

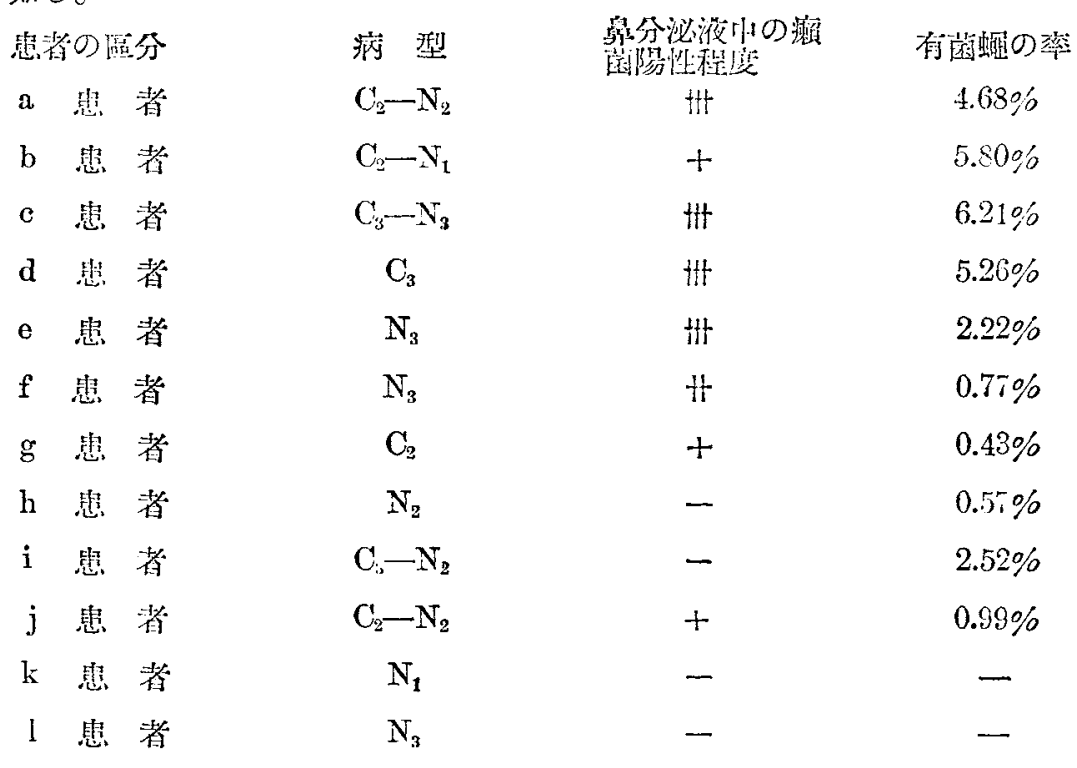

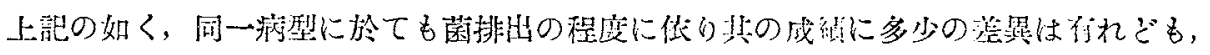

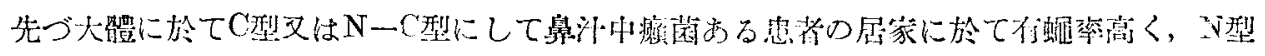
患家のものに在りては極めて低公なるふ或は全く陰叫:なり。 


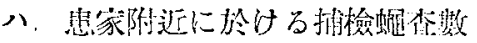

1,210匹

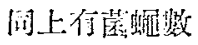

17世

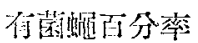

1.4

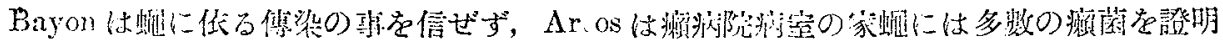

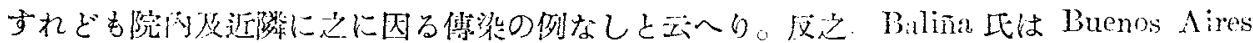

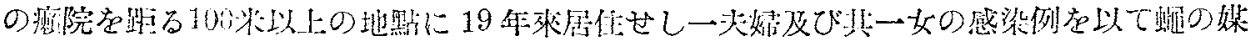
介に肖るものと胃做したり。

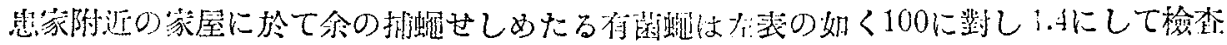

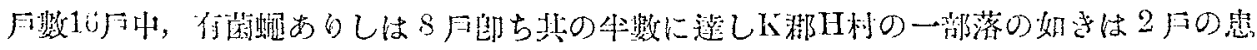

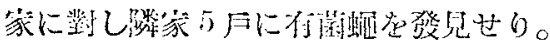

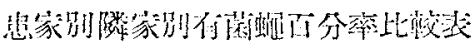

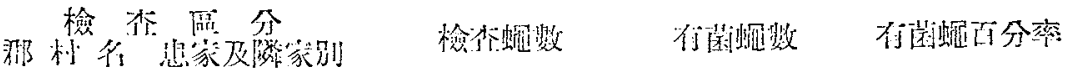

\begin{tabular}{|c|c|c|c|c|}
\hline \multirow{4}{*}{ 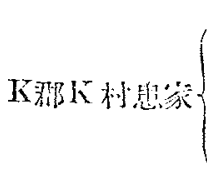 } & S. C. 宅 & $12 ?$ & 9 & 4.68 \\
\hline & F. F. 穵 & 189 & 11 & 5.82 \\
\hline & s. T. 它 & 129 & 1 & 0.78 \\
\hline & I. K. 宅 & 66 & 4 & 6.06 \\
\hline \multirow{3}{*}{ 网郡一村性家 } & S. K. 它 & 76 & 1 & 1.32 \\
\hline & T.K. 捖 & 79 & - & - \\
\hline & F.K. 它 & 89 & 1 & 1.12 \\
\hline \multirow{2}{*}{ 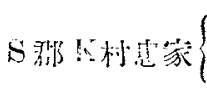 } & K. G. 宅 & 90 & 2 & 2.22 \\
\hline & [ii]星外 & 156 & 4 & 2.56 \\
\hline \multirow[t]{3}{*}{ 同那问为湿㴚 } & K.J. 焦 & 99 & 1 & $1 \cdot 01$ \\
\hline & S. S. 宅 & 175 & 1 & 0.57 \\
\hline & O.H. 宅 & 38 & 2 & 5.26 \\
\hline \multirow[t]{6}{*}{ 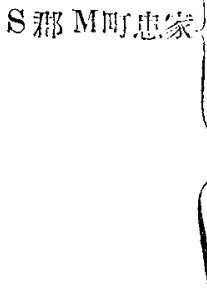 } & K. I. 肎 & 48 & - & - \\
\hline & F.K. 宅 & 78 & - & - \\
\hline & T. H. 宅 & 230 & 1 & 0.43 \\
\hline & K. B. 宅 & 36 & - & - \\
\hline & K. T. 宅 & 48 & - & - \\
\hline & M. H. 宅 & 6 & 一 & - \\
\hline \multirow[t]{4}{*}{ 同上隣家 } & T. M. 宅 & 24 & - & - \\
\hline & T. Y. 祀 & 5 & - & - \\
\hline & O. J. 宅 & 54 & - & 一 \\
\hline & M. M. 宅 & 46 & - & - \\
\hline
\end{tabular}




\begin{tabular}{|c|c|}
\hline & K. A. 宅 \\
\hline 思家 & C. K. 宅 \\
\hline & Y. K. 宅 \\
\hline & K. G. 宅 \\
\hline 何郡同祄隣筷 & C. T. 宅 \\
\hline & C. S. 宅 \\
\hline & К. 'Г. \\
\hline
\end{tabular}

159
303
65
176
87
105
54

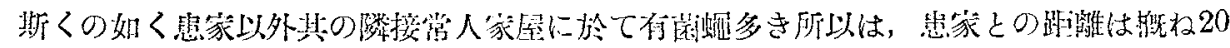

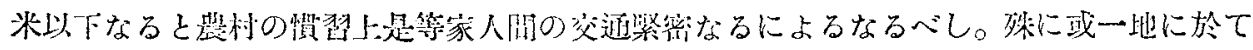

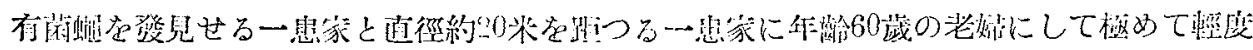

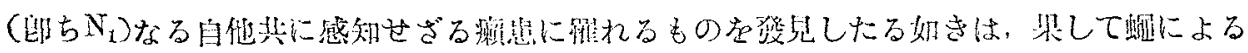

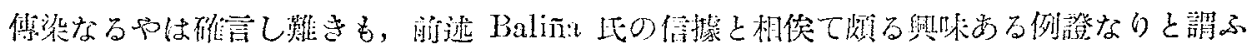

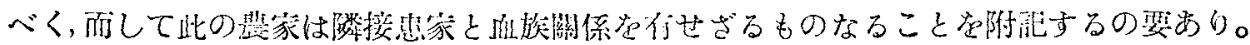

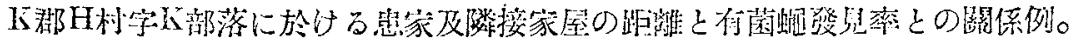

\section{（甲）第 1 列}
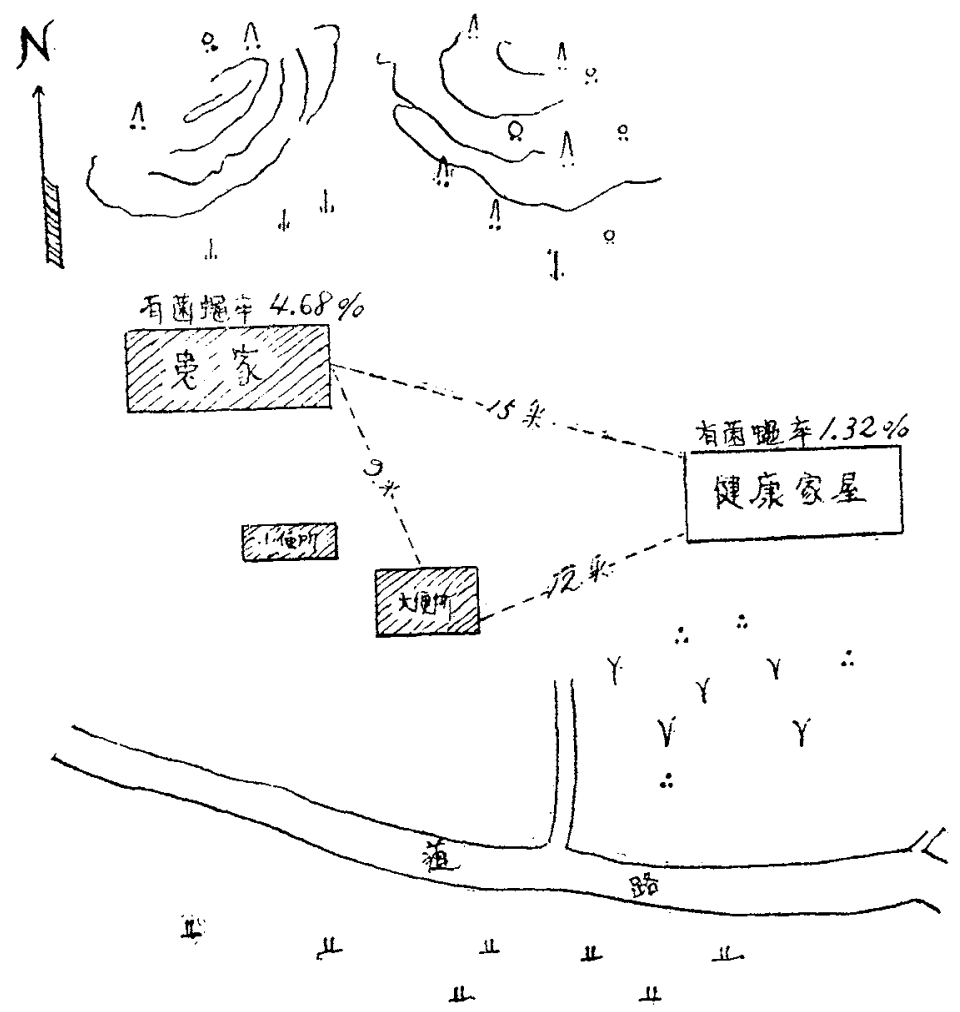

( 21$)$ 
(乙) 第 2 例

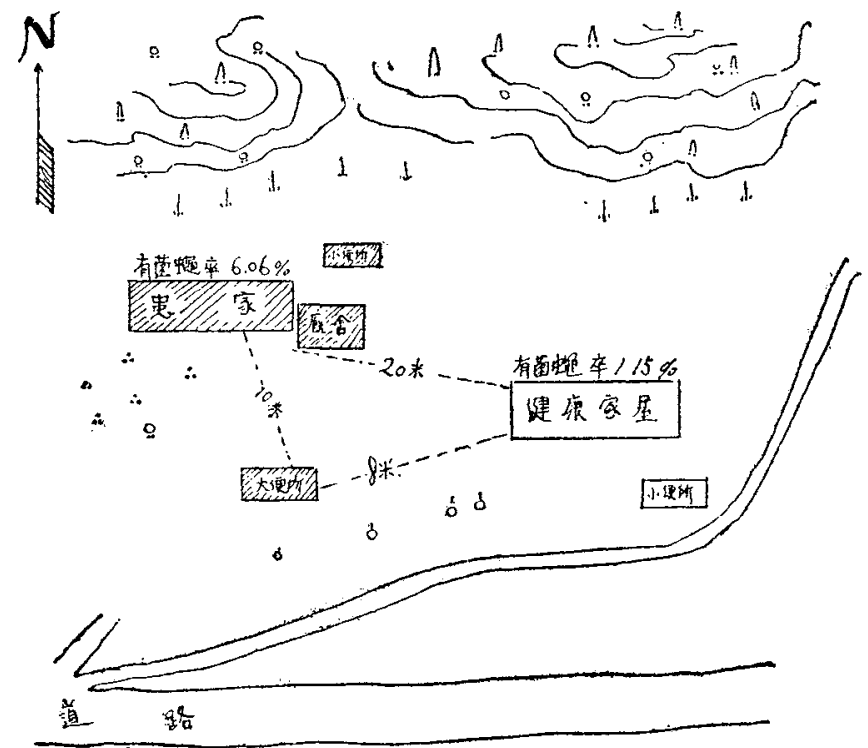

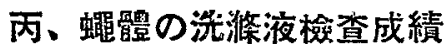

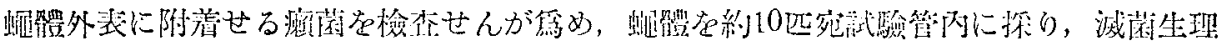

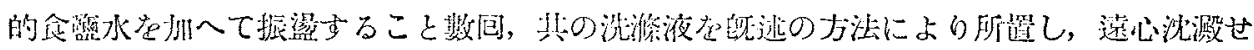

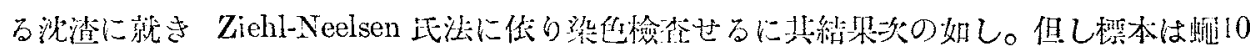
匹に就て1枚作れるものとす。

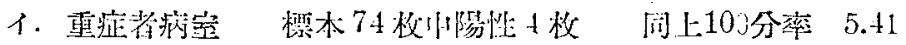

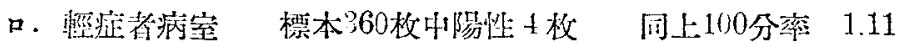

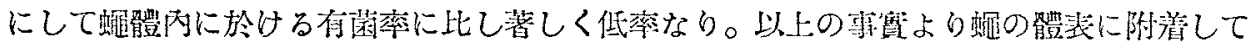

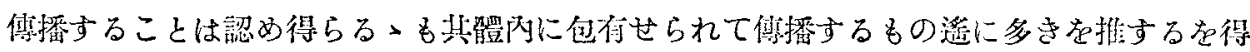
ベし。

\section{丁、蠅體內に於ける癩菌の形態}

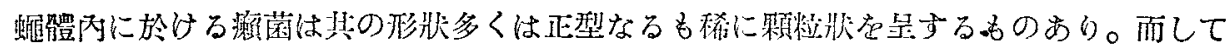

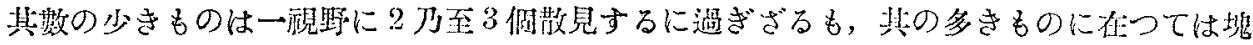

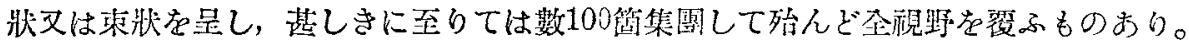




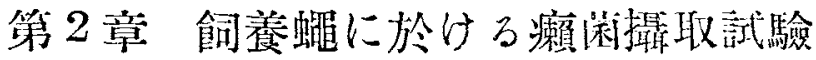

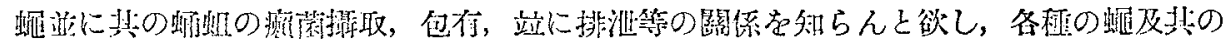

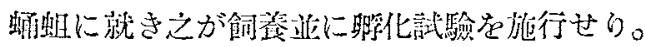

\section{甲。癩菌材棹貪食蠅の體內に於ける癞菌}

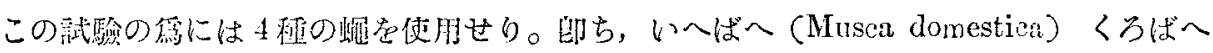
(Capilliphora lata) さんばへ(Lucilia argyrocephala) 及び,ひめいへばへ F:nnia canicularis) 是衣沶b。

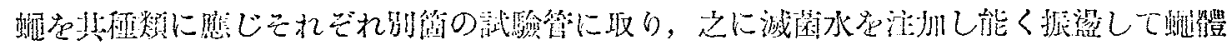

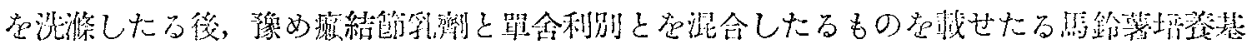

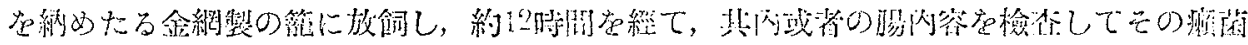

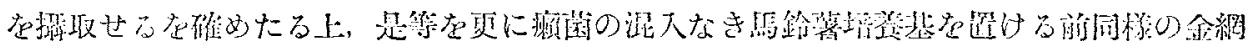

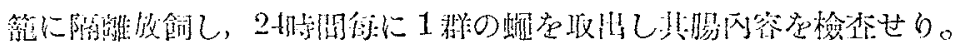

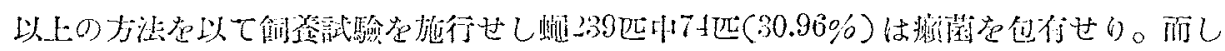

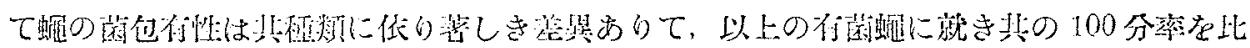

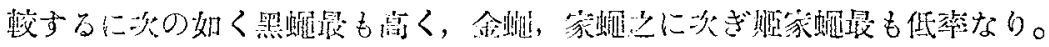

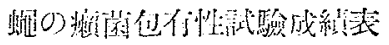

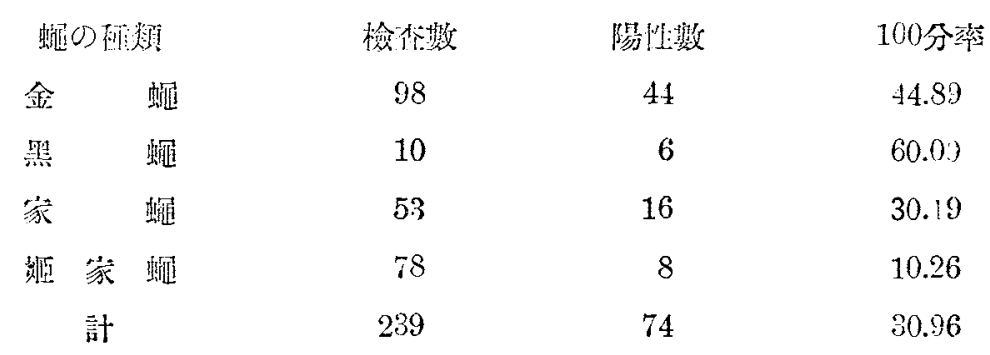

\section{乙、蠅體内に於ける癩菌の消失に要する時間}

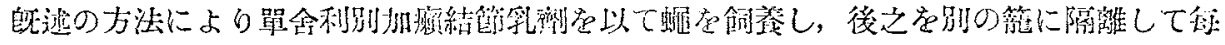

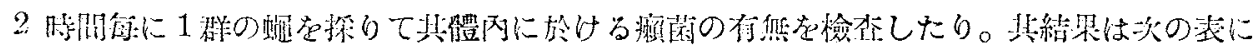

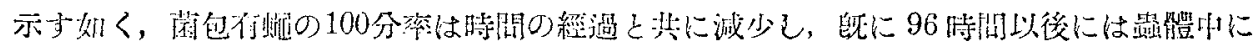

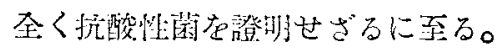

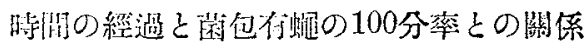


2 上

隔䠰後檢查迄の時間

24

48

72

96

120

144

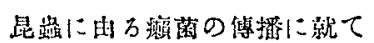

\begin{tabular}{|c|c|c|}
\hline 檢岱敖 & 陽性數 & 100分率 \\
\hline 224 & 88 & 39.29 \\
\hline 40 & 6 & 15.00 \\
\hline 61 & 5 & 8.19 \\
\hline 41 & 2 & 4.87 \\
\hline $4 s$ & - & - \\
\hline 7 & - & - \\
\hline
\end{tabular}

\section{丙、蠅體表面に於ける瀨菌}

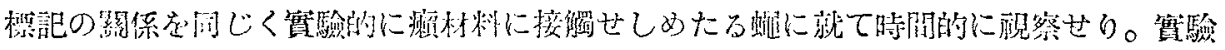

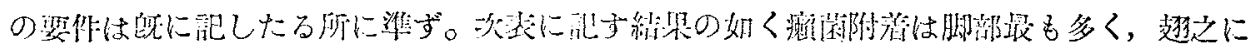

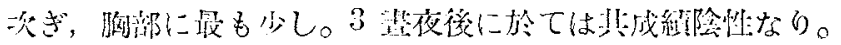

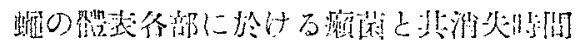

\begin{tabular}{|c|c|c|c|c|c|c|c|c|c|c|c|c|c|c|}
\hline \multicolumn{3}{|c|}{ 時 } & & 堽 & 㖡 & & 䄳 & 萑 & & 诘 & 夜 & & 4 丧 & 夜 \\
\hline \multicolumn{3}{|c|}{ 檢华政及成絽 } & & 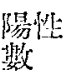 & $\begin{array}{l}100 \\
\text { 分率 }\end{array}$ & & 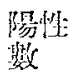 & $\begin{array}{l}100 \\
\text { 分率 }\end{array}$ & & 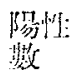 & $\begin{array}{l}100 \\
\text { 分率 }\end{array}$ & & 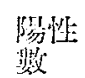 & $\begin{array}{l}100 \\
\text { 分率 }\end{array}$ \\
\hline \multirow{3}{*}{$\begin{array}{l}\text { 跑 } \\
\text { 酸 } \\
\text { 外 } \\
\text { 裴 }\end{array}$} & 抆 & 部 & $\because 3$ & 7 & 30.43 & 30 & 1 & 3.33 & $3 i$ & - & - & 30 & - & 一 \\
\hline & 趐 & 部 & 33 & 6 & 18.18 & 19 & - & - & 85 & - & - & 30 & - & - \\
\hline & 胸 & 部 & 15 & 1. & 6.6 & $2 i$ & 2 & 7.4 & 35 & 一 & - & 30 & - & - \\
\hline \multicolumn{3}{|c|}{ 竐 } & 71 & 14 & 19.72 & 76 & 3 & 3.97 & 10 & 一 & 一 & $: 0$ & - & - \\
\hline
\end{tabular}

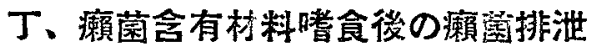

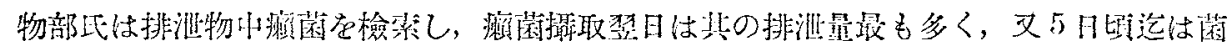

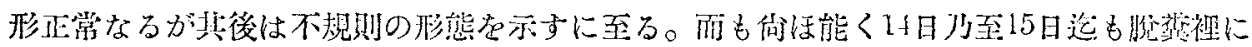
㴶菌を見鹤すと云へり。

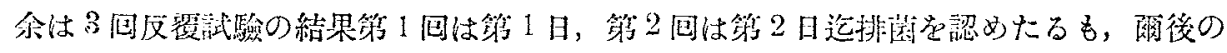
鼠便中には沃して之を發見することなかりき。

第 3 章 蠅 䖧と瀨 藏

\section{甲、蠅蛆に於ける瀨菌竝取試驗}




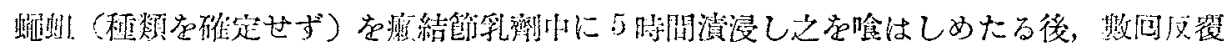

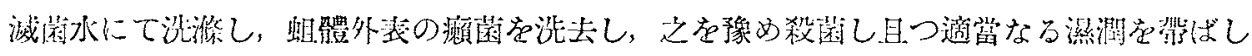

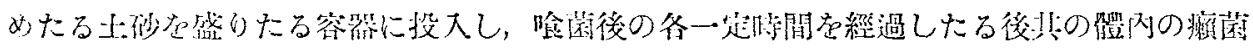

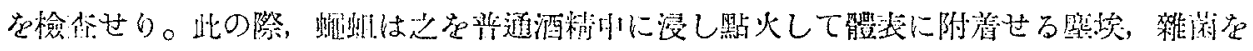

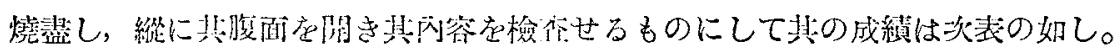

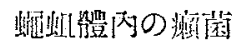

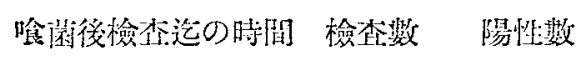

攸 考

24

72

144
11

4

3
11

2

1

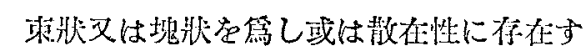
束彇在䉆す

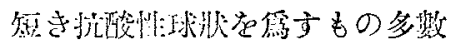

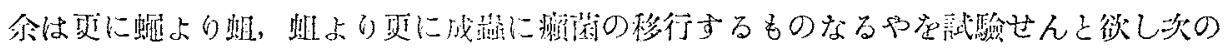

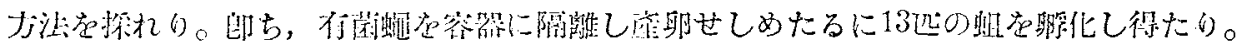

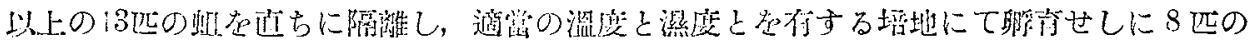

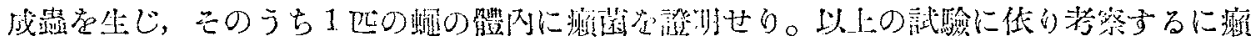

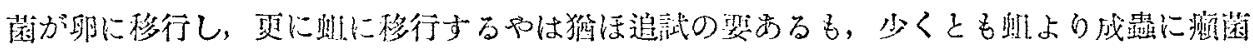

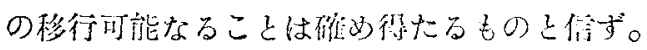

\section{乙、癩患家便所に生急する蝫蛆體內の癩菌樣抗酸性菌}

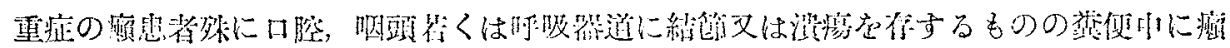

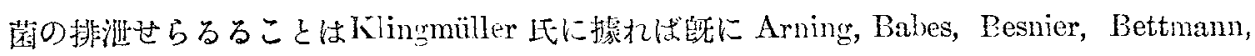
Guerra, Cappioli, Hollman, Honeij, Merian, Neeb, liavogli, Römer, Serra, Vocea \&

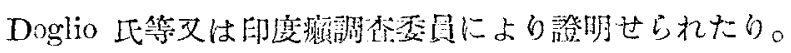

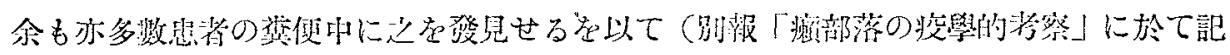

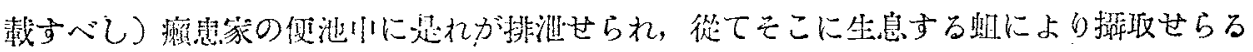
るものめるべきこと想像し難からず。

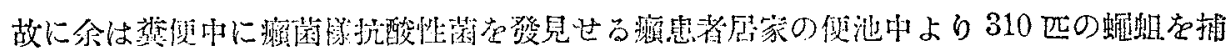

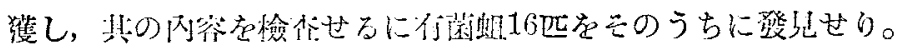

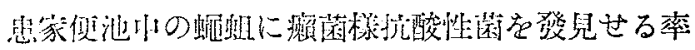

\begin{tabular}{|c|c|c|c|c|}
\hline 㭧家別 & 痛型型多! & 檢柰數 & 陽性数 & 100分率 \\
\hline Y. K. & $\mathrm{C}_{3}-\mathrm{N}_{2}$ & 94 & 4 & 4.27 \\
\hline S. T. & $\mathrm{C}_{2}-\mathrm{N}_{2}$ & 56 & 9 & 16.07 \\
\hline i. $\mathrm{F}$. & $\mathrm{C}_{2}-\mathrm{N}_{1}$ & 40 & - & - \\
\hline
\end{tabular}


O. H.

計
$\mathrm{C}_{3}$

120

310
3

2.50

16

5.16

\section{第 4 章 掻 と 癩 菌}

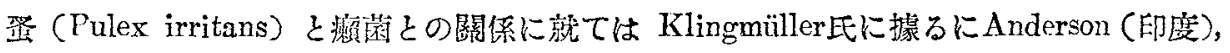
Choksy (印度), Carra quilla (Columbia), Thiroux (但し Pulex Penetrans) 氏等是㣗が

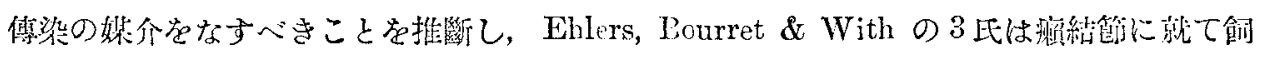

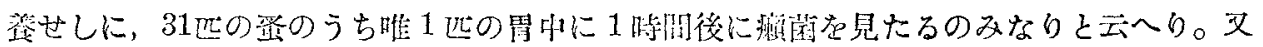

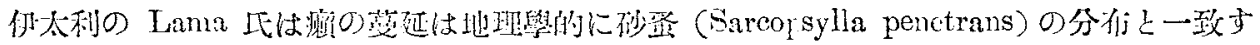

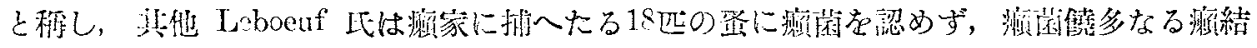

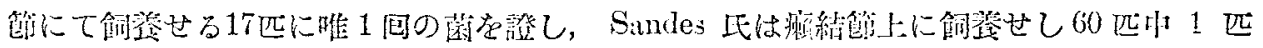
に2 侗，1匹には 1 㑉の葡在證明せり。

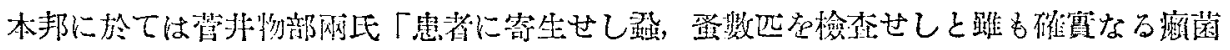
を證朋し得ず」と記せり。

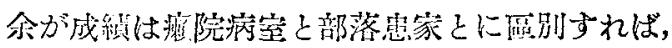

\begin{tabular}{|c|c|}
\hline 㴼院梂空 & 1,784匹怆0匹陽忙 \\
\hline 磪揤落患家 & 354 匹中 6 元陽性 \\
\hline
\end{tabular}

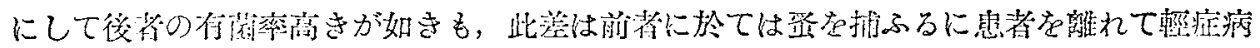

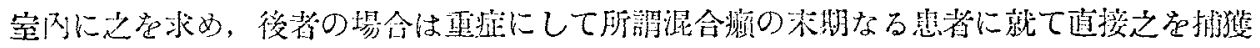
したるに印りて來れるものなるへし。

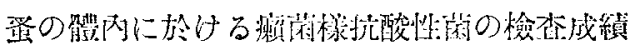

\begin{tabular}{|c|c|c|c|c|c|c|}
\hline \multicolumn{3}{|c|}{ 檢梵場所防 } & 檢证媴 & 陵性政 & 100分率 & 候＼cjkstart考 \\
\hline 濑 嵴 & 堂 & & 1,784 & 20 & 1.12 & 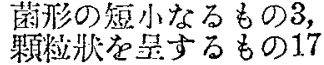 \\
\hline 瀨 村 & 名 & 患家數 & & & & \\
\hline S. & 村 & 3 & 155 & - & - & \\
\hline K. 村 & 甲 & 1 & 50 & 6 & 12.00 & 菌性正，散在性 \\
\hline 同上 & 乙 & 1 & 41 & 一 & 一 & \\
\hline M. & 村 & 1 & 28 & - & - & \\
\hline $\mathrm{H}$. & 村 & 2 & 80 & - & - & \\
\hline 計 & & 8 & 2.138 & 26 & 1.22 & \\
\hline
\end{tabular}

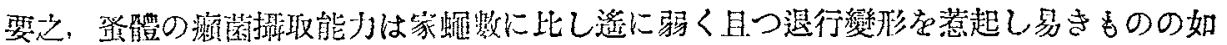




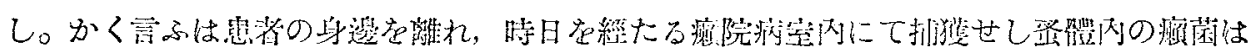

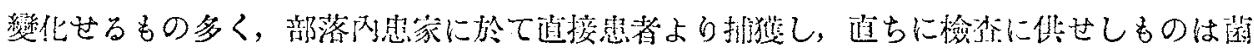
形正なるを以てなり。

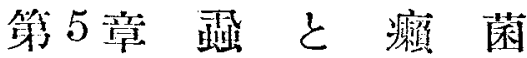

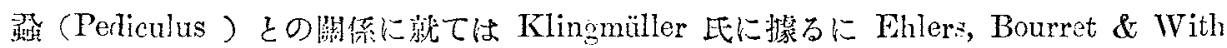

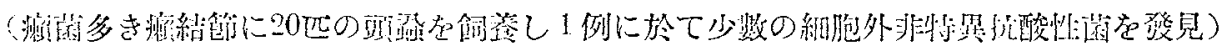

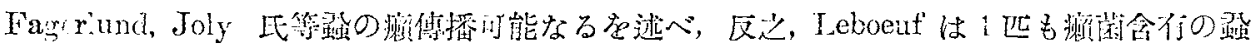

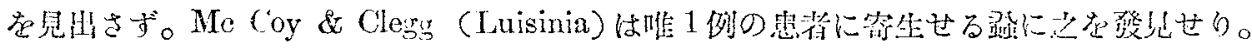

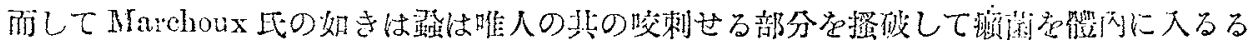

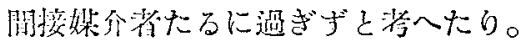

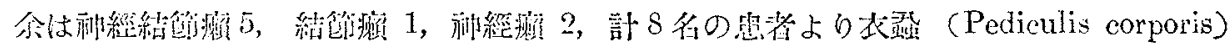

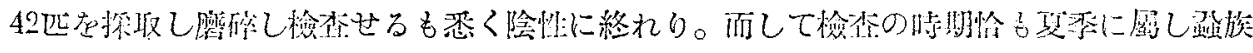

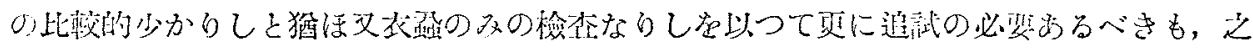

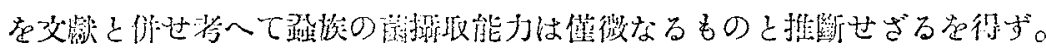

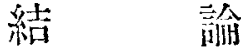

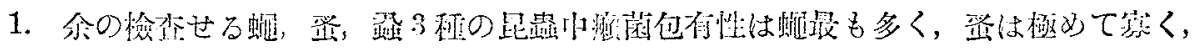

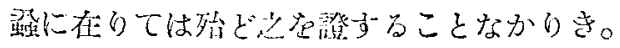

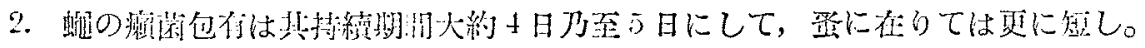

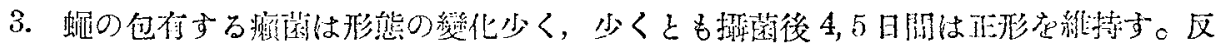

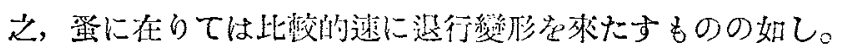

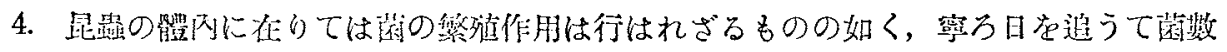
の舶しく減少するを見る。

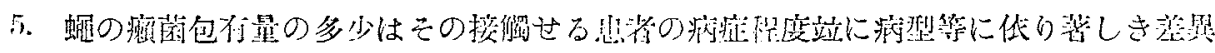

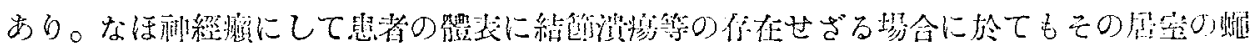

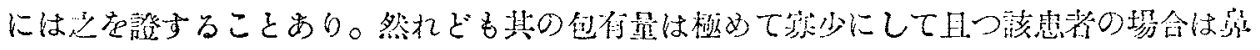

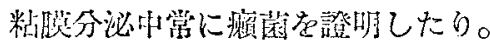

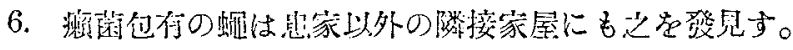

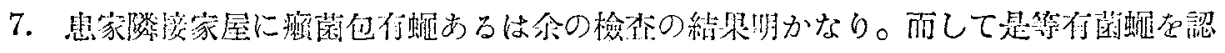

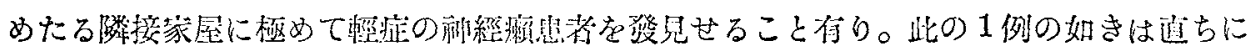




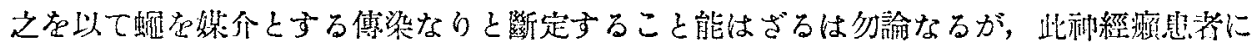

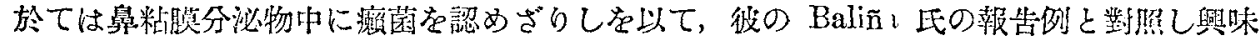
深き例なりと妬ふへしし。

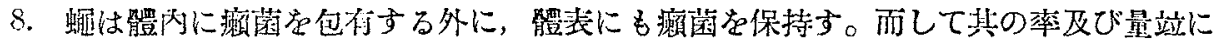
附着侍䦕は體內の場合に比し僅少なり。

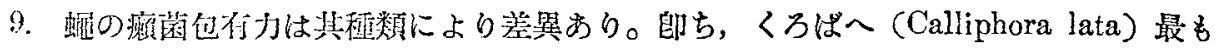
强く，きんばへ(Tucilia argyrocephara),いへばへ(Musca domestica)たに次ぎ，ひめ い代へ (Fannia canicularis) 最も少し。

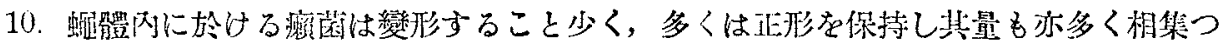

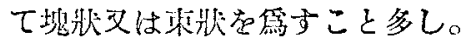

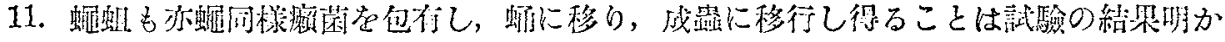

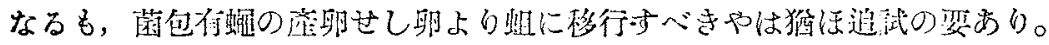

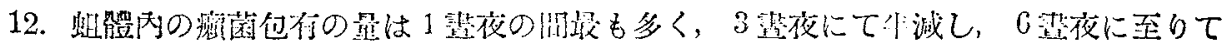

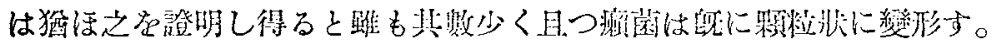

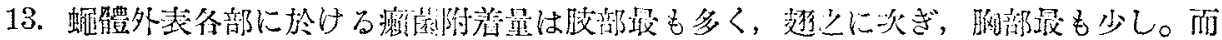

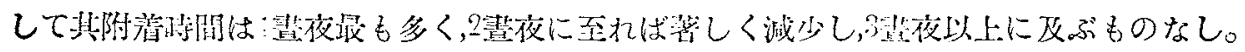

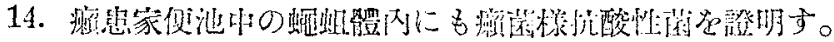

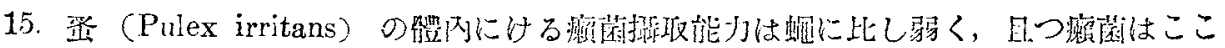

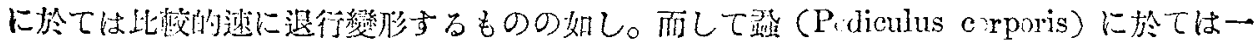
度も㴼得存證することなかりき。

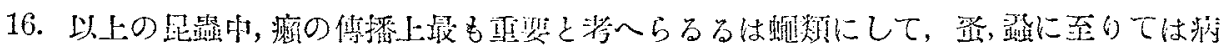

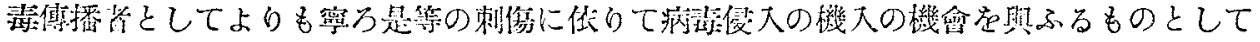
多少の想戔あるに過ぎざるべし。

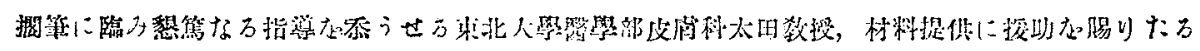

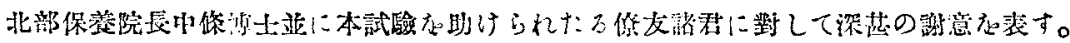

\section{參考書 目}

1) Jadassohn, J: Lepra (in Handbuch der pathogenen Microorganismen. 1928).

2) Klingmüller: Die Lepra (in Handbuch der Haut und Geschlechtskrankheiten. Berlin, 1930 .

3) Graham-Smith, G. S: Flies in Relation to Disease. Cambridge, 1914.

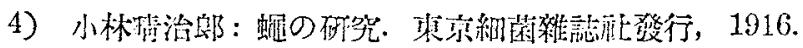

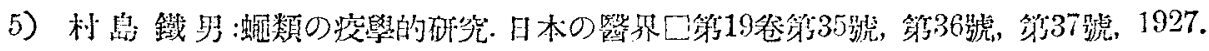

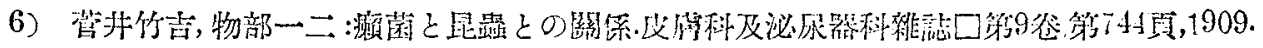

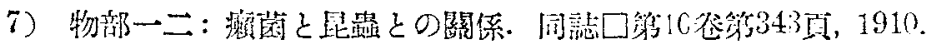

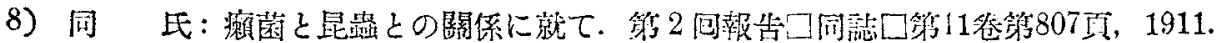


痔圆。第l。

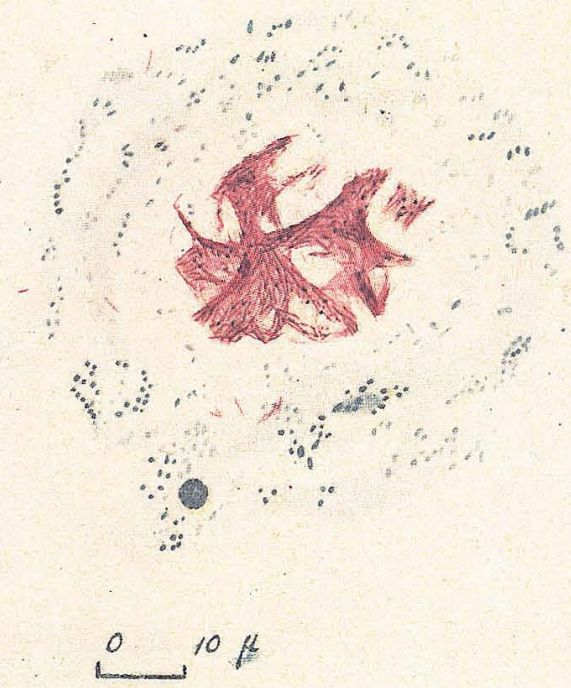

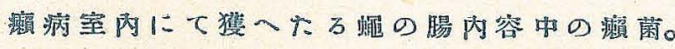
(签粙標本。チイル・ホルゼン战法による)

\section{奪圖。第2。}

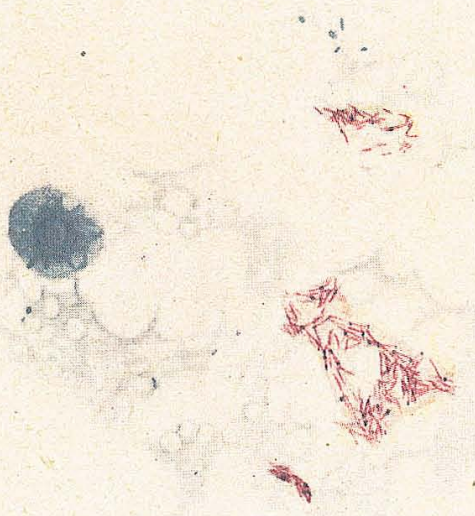

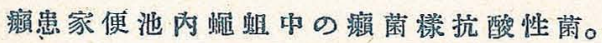
（染抹標本。チイル・ネルゼン氏染色法による）
份圖。第3。

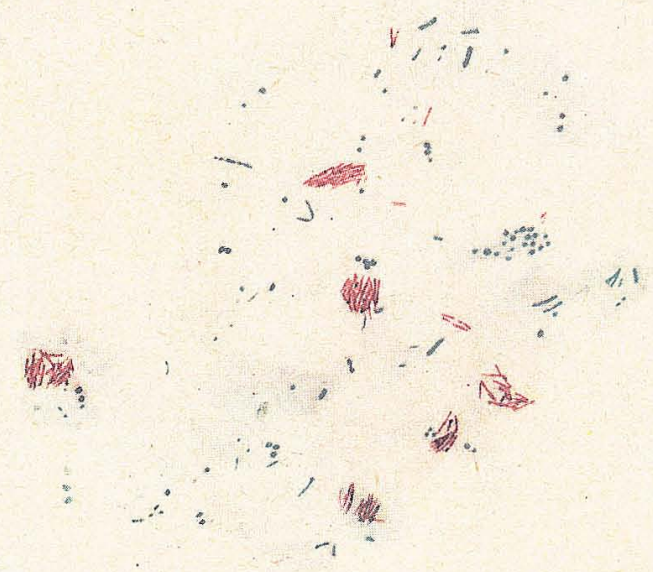

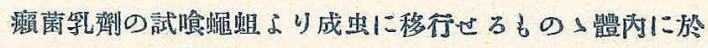

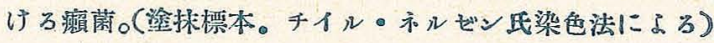

堆圖。第4。

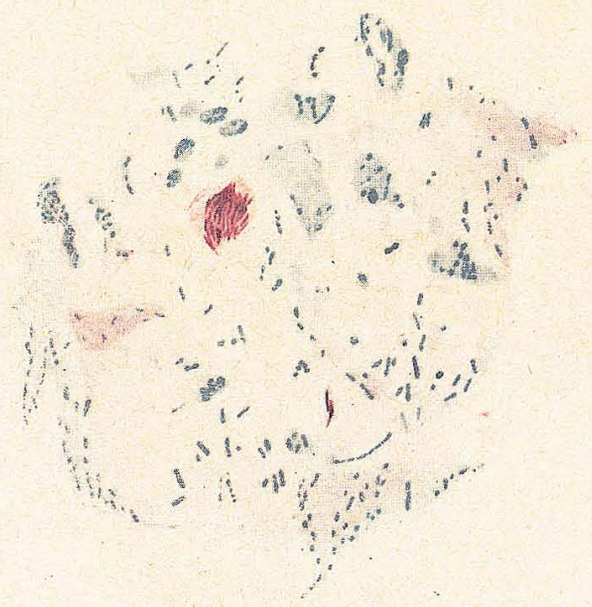

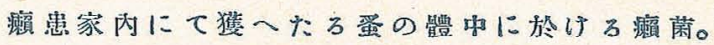
(整抹標本。チイル・ホルゼン氏染色法によら) 


\title{
UEBER VERSCHLEPPUNG DES LEPRAERREGERS DURCH INSEKTEN.
}

\author{
Von
}

\section{Shûzo Asami.}

[Aus dem Hygiene-Amt der Miyagi-Präfektur (Direktor: Sh. Asami) und aus der dermatologischen Universitätshlinik in Sendai (Director: Prof. M. Ota.)]

Die Frage, ob Insekten Lepra auf Menschen zu übertragen oder wenigstens Lepraerreger nach entfernten Bezirken zu verschleppen vermigen, ist für die Epidemiologie dieser Krankheit wichtic. Hierüber sind schon manche Untersuchungen in allen Erdteilen ausgeführt worden, wie aus den übersichtlichen Berichten von KLINGMÜLLER oder GRAHAM-SMITH zu crschen ist. Bei Gelegenheit der Zählung I_epröser in gewissen Ortschaften der MiyagiProvinz habe ich auch die Beziehung zwischen dem Lepraerreger und Insekten (Fliegen, Flöhen, Läusen) beobachtet und untersucht. Da es in Japan keine ausfïhlichen Untersuchungen über diese Frage gibt ausser denen von SUGAI und MONONOBE und da die meinigen in manchen l'unkten interessante Befunde zutage gefordert haben, so teile ich sie hier eingehend nit. Die folgenden Zeilen sind nur ein kurzer Auszug aus dieser viel längeren Abhandlung.

\section{Fliegen in Zimmern Lepröser und in Häusern der Nachbarschaft.}

Diese Frage wurde in Japan schon rgog-19 I I von SUGAI und MONONOBE behandelt. MONONOBE fand I9I I unter 15 in Krankenzimmern eines Leprosoriums gefangenen Fliegen I3 (86.3\%), die im Leibe Leprabazillen beherbergten. Er wies ferner nach, dass experimentell mit Lepramaterial gefütterte Fliegen 5-6 Tage lang Faeces ausscheiden, die unversehrte Bazillen enthalten.

Ich sammelte in 13 Krankenzimmern des Leprosoriums bei Aomori (II. Reichsleprosorium) und in 13 Privathäusern Iepröser in gewissen Ortschaften 
der Miyagi-Provinz, ferner in I6 Leprafamilien benachbarten Ifüusern (Entfernung: weniger also $20 \mathrm{~m}) 4339$ Fliegen, hauptsächlich Musca domestica, und fand darunter 2 I 7 Insekten $(5 \% \%)$, die im Leibe Leprabazillen enthiclten. Das genaucre Verhältnis ist aus folgender Trbelle zu erkennen.

\begin{tabular}{|l|c|c|c|}
\hline & $\begin{array}{c}\text { Zahl der Fliegen, in Zimmern } \\
\text { schwerer Leprakranker } \\
\text { gefangen }\end{array}$ & $\begin{array}{c}\text { Zahl der Fliegen, in Zimmern } \\
\text { relativ leichter Kranker } \\
\text { gefangen. }\end{array}$ & Summe. \\
\hline Bazillenhaltige Fligen & 447 & 896 & 1343 \\
\hline Prozentsatz. & 118 & 41 & 159 \\
\hline
\end{tabular}

\section{In Krankexzimmern von Leprafamilien.}

Zahl der gefangenen Fliegen.

1786
Zahl der bizillenhaltigen Fliegen.

41
Prozentsalz.

2.3

Dieser niedrige Prozentsatz bazillenhaltiger Fliegen in privaten I.eprahäusern erklärt sich daraus, dass die Krankenzimmer der Privatwohnugen nicht immer so streng wie in Leprasorien abgeschlossen sind. Der Prozentsatz. ist aber je nach den cinzelnen Mïuscrn verschicden und hängt im grossen und ganzen von der Schwere und der Form der Iäsionen ab. Die fogende Tabelle macht das Verhïltnis anschaulich, wonach schwere Leprakranke mit offenen Wunden mehr Bazillen nach aussen verstreuen. haltiger Fliegen.

$\begin{array}{lccc}\mathrm{a} & \mathrm{C}_{2}-\mathrm{N}_{2} & \mathrm{Ht} & 4.68 \\ \mathrm{~b} & \mathrm{C}_{22}-\mathrm{N}_{2} & + & 5.80 \\ \mathrm{c} & \mathrm{C}_{3}-\mathrm{N}_{3} & \mathrm{H} & 6.21 \\ \mathrm{~d} & \mathrm{C}_{3} & \mathrm{Ht} & 5.26 \\ \mathrm{e} & \mathrm{N}_{3} & \mathrm{Ht} & 2.22 \\ \mathrm{f} & \mathrm{N}_{3} & \mathrm{H} & 0.77 \\ \mathrm{~g} & \mathrm{C}_{2} & + & 0.43 \\ \mathrm{~h} & \mathrm{~N}_{2} & - & 0.57 \\ \mathrm{i} & \mathrm{C}_{3}-\mathrm{N}_{2} & - & 2.5 \dot{2}\end{array}$




$\begin{array}{llll}\mathbf{j} & \mathrm{C}_{2}-\mathrm{N}_{2} & + & 0.99 \\ \mathbf{k} & \mathrm{N}_{1} & - & - \\ \mathbf{l} & \mathrm{N}_{3} & - & -\end{array}$

3. In Wohnungen Lepröser und in deren Nachbarschaft.

\begin{tabular}{|c|c|c|c|c|}
\hline Untersuchte Ortschaften. & $\begin{array}{l}\text { Name der } \\
\text { Kranken bzw. } \\
\text { des Wirts. }\end{array}$ & $\begin{array}{l}\text { Zahl der } \\
\text { gefangenen } \\
\text { Flisgen. }\end{array}$ & $\begin{array}{l}\text { Zahl der } \\
\text { bazillenhalti- } \\
\text { gen Fiiegen. }\end{array}$ & Prozentsatz \\
\hline \multirow{4}{*}{$\begin{array}{l}\text { K-K. } \\
\text { (in Häusern von Kranken) }\end{array}$} & S. C. & 192 & 9 & 4.68 \\
\hline & $\mathrm{T} . \mathrm{F}$ & 189 & 11 & 5.82 \\
\hline & S. J. & 129 & 1 & 0.78 \\
\hline & I. $\mathrm{K}$. & 66 & 4 & 6.06 \\
\hline \multirow{3}{*}{$\begin{array}{c}\text { Dieselbe Ortschaft } \\
\text { (in nicht infizierten } \\
\text { H insern der } \\
\text { Nachbarschaft: }\end{array}$} & S. K. & 76 & 1 & 1.32 \\
\hline & T. K. & 79 & 0 & 0 \\
\hline & T. K. & 89 & 1 & 1.12 \\
\hline \multirow{2}{*}{$\begin{array}{l}\text { S.-K. } \\
\text { (im Haus von Kranken) }\end{array}$} & (im Zimmer) & 90 & 2 & 2.22 \\
\hline & $\begin{array}{c}\text { K. G. } \\
\text { (ausserhalb des } \\
\text { Hauses) }\end{array}$ & 156 & 4 & 2.56 \\
\hline $\begin{array}{c}\text { Dieselbe Ortschaft } \\
\text { (Nicht infiziertes } \\
\text { Nachbarhaus) }\end{array}$ & K. J. & 99 & 1 & 1.01 \\
\hline \multirow{5}{*}{$\begin{array}{l}\text { S.-M. } \\
\text { (in Häusern von Kranken) }\end{array}$} & S. S. & 175 & 1 & 0.57 \\
\hline & O. H. & 38 & 2 & 5.26 \\
\hline & K. J. & 48 & 0 & - \\
\hline & F. K. & 78 & 0 & - \\
\hline & T. H. & 230 & 1 & 0.43 \\
\hline \multirow{6}{*}{$\begin{array}{c}\text { Dieselbe Ortschaft } \\
\text { (in nicht infizierten } \\
\text { Hiusern der } \\
\text { Nachberschaft) }\end{array}$} & K. B. & 36 & 0 & - \\
\hline & K. T. & 48 & 0 & - \\
\hline & M. H. & 6 & 0 & - \\
\hline & T. $M$ & 24 & 0 & $\longrightarrow$ \\
\hline & T. Y. & 5 & 0 & - \\
\hline & O. J. & 54 & 0 & - \\
\hline
\end{tabular}




\begin{tabular}{|c|c|c|c|c|}
\hline & M. M. & 46 & 0 & $\ldots$ \\
\hline \multirow{2}{*}{$\begin{array}{l}\text { K.H. } \\
\text { (in Häusern von Kranken) }\end{array}$} & K. A. & 159 & 4 & \multirow{2}{*}{$-\frac{2.52}{0.99}$} \\
\hline & C. $K$. & 303 & 3 & \\
\hline \multirow{5}{*}{$\begin{array}{c}\text { Dieselbe Ortschaft } \\
\text { (in nicht infizierten } \\
\text { H.usern der } \\
\text { Nachbarschaft) }\end{array}$} & Y. K. & 65 & 2 & 3.08 \\
\hline & K. G. & 176 & 4 & 2.26 \\
\hline & C. T. & 87 & 1 & 1.14 \\
\hline & C. S. & 105 & 4 & 3.81 \\
\hline & K. T. & 54 & 2 & 3.70 \\
\hline
\end{tabular}

Die Bazillen im Leibe der Fliegen zeigen meist die typische Stäbchenform und sind zuweilen granulös. Die Bazillenzahl bei einer Fliege ist verschieden, von ein paar Stäbchen in einem Gesichtsfeld bis zu massenhaften Konglomeraten von Bazillen.

\section{Leprabazillen aussen am Körper der Fliegen.}

Je to der in Krankenzimmern des Leprosoriums gefangenen Fliegen wurden in ein Glasröhrchen getan und unter Schütteln mit Wasser ausgewaschen. Vom Bodensatz jedes Röhrchens wurde I Präparat hergestellt.

Zahl der im Krankenzimmer Zahl der Präparate. Positive Fälle. Prozentsatz. gefangenen Fliegen.

Bei schweren

$\begin{array}{lcccc}\begin{array}{l}\text { Bei schweren } \\ \text { Kranken }\end{array} & 740 & 74 & 4 & 5.41 \\ \begin{array}{l}\text { Bei relativ } \\ \text { leichten }\end{array} & 3600 & 360 & 4 & 1.11 \\ \text { Kranken. } & & & & \end{array}$

Man vermutet daraus, dass die Zahl der Bazillen aussen am Fliegenkörper viel geringer als im Leibe ist.

\section{Fütterungsprobe von Fliegen mit leprösem Material.}

\section{Leprabazillen im Leibe der Fliegen.}

Für diesen Versuch wurden 4 Fliegenarten gebraucht: Musca domestica, Capilliphora lata, Lucilia argyrocephala und Fannia canicularis. Die Fliegen wurden vorerst mit sterilem Wasser gewaschen und nach I2 stündiger Füt- 
terung mit bazillenreichem Leprombrei + Sirup in einem anderen Behälter mit leprabazillenfriem Futter ernährt. Alle 24 Stunden danach habe ich die Leprabazillen in ihrem Leibe untersucht. Das Ergebnis its, wie folgt.

Arten der Fliegen. Zahl der untersuchten Zahl der bazillen- Prozantsatz. Fliegen. haltigen Fliegen.

\begin{tabular}{lccc} 
Capilliphora lata. & 10 & 6 & 60.00 \\
Lucilia argyrocephala. & 98 & 44 & 44.89 \\
Masca domestica. & 53 & 16 & 30.19 \\
Fonnia canicularis. & 78 & 8 & 10.26 \\
\hline Summe & 239 & 74 & 30.96
\end{tabular}

\section{Dauer des Verbleibens der Leprabazillen im Leibe der Fliegen.}

\begin{tabular}{|c|c|c|c|}
\hline $\begin{array}{l}\text { Zeitdauer nach Aufhüren } \\
\text { der Fütterung mit }\end{array}$ & $\begin{array}{c}\text { Zahl der untersuchten } \\
\text { Fliegen }\end{array}$ & $\begin{array}{l}\text { Zahl der bazillen- } \\
\text { haltigen Fliegen. }\end{array}$ & Prozent: \\
\hline \multicolumn{4}{|l|}{ leprainfiziertem Material } \\
\hline $24 \operatorname{Stdn}$ & 224 & 88 & $39 . .9$ \\
\hline $48 \prime \prime$ & 40 & 6 & 15.00 \\
\hline $72 \prime \prime$ & 61 & 5 & 8.19 \\
\hline $96 \prime \prime$ & 41 & 2 & 4.87 \\
\hline $1 \approx 0 \quad "$ & 48 & - & - \\
\hline $144 \prime \prime$ & 8 & - & - \\
\hline
\end{tabular}

Die aussen an den Fliegen haftenden Bazillen verschwinden nach 3 Tagen spuros; sie werden in den Faeces der Fliegen bis zum Finde des zweiten Tages nachzewiesen.

\section{Fliegenlarven.}

Die mit Lepramaterial gefütterten Larven beherbergen auch Leprabazillen in ihrem Leibe, wenigstens bis $z \mathrm{u}$ I44 Stunden nach dem Aufhören der Fütterung mit leprabeflecktem Futter.

Ich bekam ferner durch Züchtung von I 3 Larven, die von mit leprösem Material infizierten Fliegen herstammten, 8 neue Fliegen, unter denen eine in ihrem Leibe noch ziemlich viele säurefeste Säbchen enthielt.

Unter 3 ro Fliegenlarven, aus Kotgruben lepröser Familien gesammelt, fand ich 16 , die säurefeste Stäbchen (waerscheinlich Leprabazillen) beherbergten. 


\begin{tabular}{c|c|c|c|c}
\hline Kranke & Krankheitstypus & $\begin{array}{c}\text { Zahl der untersucht } \\
\text { en Larven }\end{array}$ & $\begin{array}{c}\text { Zahl der bazillen- } \\
\text { tragenden Larven }\end{array}$ & Prozentsatz \\
\hline Y. K. & $\mathrm{C}_{3}-\mathrm{N}_{3}$ & 94 & 4 & 4.27 \\
\hline S. T. & $\mathrm{C}_{-}-\mathrm{N}_{1}$ & 56 & 9 & 16.07 \\
\hline T. F. & $\mathrm{C}_{2}-\mathrm{N}_{1}$ & 40 & - & - \\
\hline O. H. & $\mathrm{C}_{3}$ & 120 & 3 & 2.50 \\
\hline & Summe & 310 & 16 & 5.16 \\
\hline
\end{tabular}

\section{Pulex irritans.}

SUG II und MONONOBE berichteten, dass sie an den von Leprösen genomm:n Flöhen und Läusen niemal:; Leprabazillen nachgewiesen haben. Ich fand sie aber unter $178_{4}$ in Lankenzimmern des Leprosoriums gefangenen Flohen 20 Mal ( I.12 \% $\%$ ), und unter 354 in Zimmern von Privatwohnungen Lepröser gefanghhen 6 Mal (1.69\%). Dis Bazillen im Leibe der Flöhe waren immer von degenerierter Form.

\section{Pediculus corporis.}

Bei keiner der 42 Läuse, die bei 8 Leprösen (Lepra mixta : 5, I. tuberosa : I und L. nervorum 2) schmarotzten, konnte ich Lepratreger nachweisen. (Autoref.)

\section{ERHL $\ddot{A R U N G ~ D E R ~ A B B I L D U N G E N . ~}$}

I. Leprabazillen im Verdaungstraktus einer Fliege, die im Krankenzimmer eines Leprosoriums gefangen wurde.

2. Leprabazillen in Verdauungstraktus einer Fliegenlarve, die in der Kotgrube beim Hause eines Leprösen gefangen wurde.

3. Leprabazilleu im Verdaungstraktus einer Fliege, die sich aus einner mit leprom Material gefütterten Larve entpuppt hatte.

4. Leprabazillen im Leibe eines Flohs, im Krrnkenzimmer einer Leprafamilie gefangen. 